\title{
La Guerra Fría en América Latina
}

Reseñas

Héctor Saúl Bravo Rosete ${ }^{1}$ (D) https://orcid.org/0000-0002-1067-9390

Centro de Estudios Históricos

El Colegio de México

kraggertz@hotmail.com

Vanni Pettiná, La Guerra Fría en América Latina, México, El Colegio de México, 2018, 260 pp. ISBN 978-607-628-249-6

En esta obra del Doctor Pettiná, perteneciente a la colección "Historia mínima” que publica el Colegio de México, se hacen visibles los objetivos que han guiado al proyecto editorial comenzado por Cosío Villegas a inicios de la década de los setenta y que recientemente ha cobrado un nuevo ímpetu. La síntesis y el carácter de divulgación como pilares de la colección, dan carácter y forma al texto sin que esto demerite el rigor académico. Para ello se ha prescindido de las citas y notas al pie de página, con la idea de convertirse en una lectura fluida y apta para todo público; para no espantar con letras pequeñas al ojo que recién inicia en el tema o la disciplina histórica, pero tampoco que aleje al especialista con generalidades carentes de la frescura que dan los análisis y las ideas nuevas. Y, cumpliendo hasta las últimas páginas con los objetivos antes mencionados, en lugar de entregar una lista larga, fría y ordenada alfabéticamente de la bibliografía que el autor utilizó y mencionó a lo largo del texto, se entrega un "Ensayo bibliográfico". Dicho ensayo se acopla temáticamente al índice, siendo de cinco secciones correspondientes a cada capítulo del libro. En cada sección el autor desglosa y

\footnotetext{
${ }^{1}$ Doctorante en Historia del Centro de Estudios Históricos, El Colegio de México.
} 
comenta sucintamente las obras más relevantes y reconocidas, y también aquellas que se dedican a un tema muy específico, como un país o un proceso que no se pudo abarcar profundamente en el texto. Los comentarios se convierten en una guía de lectura para seguir entre la amplia bibliografía existente sobre Latinoamérica, apuntando directamente al periodo que trata el libro, La Guerra Fría. Con ello, el lector puede seguir los pasos bibliográficos que dio el autor para escribir cada sección temática y ahondar en los conocimientos que respaldan la estructura del capitulado según sus propios intereses.

La Guerra Fría en América Latina, también es parte de una de las secciones más ambiciosas del proyecto de "Historia mínima", dedicada, como lo indica el título, al abordaje de temas que se ubican en tan amplia geografía como lo es el territorio latinoamericano. Lo cual convierte a esta sección de la colección y a la obra del Dr. Pettiná, en un polo de la historiografía de habla hispana. Ello al plantear una perspectiva metodológica cuyo fundamento es el reconocimiento de Latinoamérica como un espacio integral que comparte cualidades históricas, políticas, económicas y culturales. Por lo tanto, uno de los atributos de la obra es que analiza en conjunto a la región sin que se convierta en una historia fragmentada por naciones o la historia de regiones y subregiones separadas. De esta manera, la colección y el libro, ponen en perspectiva la labor burocrática, política y académica que ha significado buscar el conocimiento (y reconocimiento como problema de estudio) de una región latinoamericana. Labor que comenzó a finales de la década de los setenta, justo durante la etapa más álgida y violenta de la Guerra Fría, y que tomó forma en varias instituciones académicas en las que participaron varios países ${ }^{2}$ Y Y que ahora, dicho proyecto de integración

\footnotetext{
${ }^{2}$ Ejemplos como la Facultad Latinoamericana de Ciencias Sociales, fundada en 1957, cuya sede en México data desde 1975, la Sociedad de Estudios sobre América Latina y el Caribe (1978) y la Federación Internacional de Estudios sobre América Latina y el Caribe. En México, los esfuerzos de la UNAM a partir de la fundación del Colegio de Estudios Latinoamericanos y el Centro de Estudio sobre América Latina y el Caribe.
}

Secuencia. E-ISSN 2395-8464 
académica cobra vida en un emprendimiento editorial de El Colegio de México y que tiene entre su colección esta obra cuyo tema atañe profundamente a la región.

Como el mismo autor menciona desde las primeras páginas, la historiografía sobre la Guerra Fría tiene varias generaciones de estarse escribiendo, pero muy recientemente comienza a atender al Tercer Mundo, al africano y al latinoamericano. Además, como también señala el autor, han sido muy variadas y preeminentes las investigaciones que no pertenecen al habla hispana. Con lo cual, la obra del Dr. Pettiná, viene a saldar varios vacíos historiográficos al ser un trabajo que hace un esfuerzo por integrar como objeto de estudio la región latinoamericana, hacerlo con el tema de la Guerra Fría, colocándose como uno de los primeros en hacerlo en español y por último, entregar una importante síntesis historiográfica de las investigaciones que a la fecha se han realizado y de las que se están realizando en el presente año.

Pero las contribuciones de la obra no solamente se hayan en el ámbito historiográfico, también en el terreno analítico. Ya que el autor coloca conceptos y propone una cronología que se puede implementar para próximos estudios. Con este libro el Dr. Pettiná abre la discusión sobre lo que significa conjuntar dos procesos que hemisféricamente aparecían solamente como una confrontación entre dos polos. Donde Norte y Sur se tocaban únicamente por la intervención norteamericana y que en esta obra son presentados con una nueva veta de investigación donde cada país tiene independencia y capacidad de decisión en los procesos políticos y económicos sin perder una perspectiva de conjunto. La síntesis que realiza el autor es de tal manera reveladora que muestra cómo fue el impacto de la Guerra Fría en cada país sin que esto signifique tener una visión nacionalista y donde, por el contrario, se puede observar cómo la política norteamericana cambió de acuerdo a sus intereses y cómo cada país respondió a los suyos propios a partir de 1947. Por lo tanto, los objetivos y retos que Secuencia. E-ISSN 2395-8464 
se plantea la obra son cumplidos al mencionar que no busca ser episódica y tampoco una muestra de los momentos más álgidos, sino que busca mostrar los procesos que se dieron desde la perspectiva regional, así como los que se vincularon al más amplio tema de la Guerra Fría.

En términos concretos, se está ante una obra que aborda el tema con atención a los procesos más significativos, atendiendo al gran marco del conflicto bipolar y mostrando cómo fue que trastocó la evolución política y económica de la región. Para ello se sirve de una estructura narrativa que comprende cuatro secciones. La primera, planteada como la "Guerra Fría Temprana”, en la que el conflicto se centra en la manera que debería impulsarse el desarrollo económico de la región latinoamericana, y en la que se presentan las cualidades políticas y las distintas agendas internacionales que asumió cada país. En la segunda parte denominada "La inflexión de la Revolución Cubana”, se muestra cómo la izquierda cambió y cómo un sector de ésta se radicalizó para formar guerrillas, proceso que fue distinto en cada país, correspondiendo a las cualidades de las elites, los partidos locales, la presencia de militares y la manera en que E. U. se aprestó a intervenir. La tercera parte, "La década del terror”, muestra cómo fue el ascenso de la violencia y de los regímenes militares, así como la polarización social y los distintos apoyos que brindaron entre naciones, ya fuera para armar guerrillas o ya fuera para impedir su crecimiento, periodo que también ha sido denominado como "La Guerra Fría Interamericana". Por último, el "Conflicto político-militar centroamericano”, periodo en que el foco se movió de países y en el que la violencia no fue el único medio para atajar el conflicto, ponderándose las relaciones diplomáticas y los apoyos internacionales.

Reseñar un libro sería una labor incompleta si no se menciona el trabajo editorial que se hizo para concretarlo. Trabajo que muchas veces queda en la oscuridad pero que merece Secuencia. E-ISSN 2395-8464 
ser resaltado, en este caso, por tres motivos. El primero, el agradecimiento que hace el Dr. Pettiná a Ana González Masegosa, por el trabajo de edición traduciendo el itañol del autor a un español más entendible (como él mismo confiesa). Situación que el lector agradece con las buenas traducciones literarias e historiográficas. El segundo motivo, es la portada del libro que presenta una obra del artista cubano Rafael Morante, Muerte al invasor (1962). El dibujo fue creado para uno de los varios carteles que promocionaron en Cuba, Latinoamérica y Europa, el trabajo cinematográfico y documental que mostró al mundo un filme de quince minutos grabados durante la invasión a Bahía de Cochinos. La portada remite a un cuestionamiento cuya respuesta queda pendiente ¿qué sucedió en el ámbito cultural y científico durante la Guerra Fría y cómo fue afectada por el conflicto? El autor cita varios libros que aluden al tema pero que por ser pocos, hacen notorio que necesita ser más investigado. Y aquí el tercer motivo, el ámbito cultural, que con la elección de la portada queda abierta la propuesta. Hace falta saber cuál fue la labor de los intelectuales, qué sucedió con la música, los deportistas, los artistas (pintores, literatos, cineastas), durante el periodo en cuestión. En términos generales, la buena traducción y la elección de una imagen muy acorde al tema en su portada, completado con colores que remiten estéticamente al verde olivo del militarismo vivido en América Latina durante la Guerra Fría, añaden a la obra de investigación una bella forma del libro.

Secuencia. E-ISSN 2395-8464 